\title{
Formando a futuros maestros para abordar los microorganismos mediante actividades prácticas. Papel de las emociones y valoraciones de los estudiantes
}

\author{
José María Marcos Merino \\ Departamento de Didáctica de las Ciencias Experimentales y las Matemáticas, Facultad de Educación, \\ Universidad de Extremadura.Badajoz, España.jmmarcos@unex.es \\ ORCID: bttp:/ / orcid.org/0000-0003-0773-2899 \\ Rocío Esteban Gallego \\ Departamento de Didáctica de las Ciencias Experimentales y las Matemáticas, Facultad de Educación, \\ Universidad de Extremadura.Badajoz, España.rocioesteban@unex.es \\ ORCID: https:/ / orcid.org/0000-0002-4610-4732
}

Jesús Gómez Ochoa de Alda

Departamento de Didáctica de las Ciencias Experimentales y las Matemáticas, Facultad de Formación del Profesorado, Universidad de Extremadura. Cáceres, España.ochoadealda@unex.es

ORCID: https:// orcid.org/0000-0002-4688-2470

[Recibido: 6 Junio 2018. Revisado: 23 Agosto 2018. Aceptado: 3 Septiembre 2018]

\begin{abstract}
Resumen: Para promover la motivación y el aprendizaje sobre los microorganismos se ha recomendado implementar actividades prácticas. Sin embargo, los docentes realizan pocas prácticas de Microbiología, área en la que, al igual que sus alumnos, presentan ideas alternativas. Dada esta situación, es necesario formar a los futuros docentes en la enseñanza de los microorganismos. En el presente trabajo se describe una práctica para la enseñanza de conceptos microbiológicos básicos a maestros en formación inicial, así como los resultados de su implementación en el aprendizaje y las emociones de los participantes. Los resultados muestran que dicha práctica es efectiva, motivante y bien valorada por los participantes en relación a su futuro profesional; observándose correlaciones entre estos aspectos. En concreto, se han detectado asociaciones positivas entre las emociones positivas y los resultados de aprendizaje, y entre estos y el valor otorgado a la práctica; así como una asociación negativa entre las emociones negativas y los resultados de aprendizaje.
\end{abstract}

Palabras clave: Microbiología, Educación Primaria, enseñanza práctica, formación inicial, emociones

Training future Primary teachers to approach microorganisms through practical activities. Role of students' emotions and values

Abstract: In order to foster motivation and learning about microorganisms, the implementation of practical activities has been recommended. However, Primary teachers rarely perform Microbiology practices, a branch of science in which they hold some misconceptions, like their students. To reverse this situation, it is necessary to develop the ability to teach these practices in prospective teachers. In this contribution we describe a practice to teach basic microbiological concepts to prospective Primary teachers, as well as the effect of its implementation in students learning outcomes and their emotions. Results show that the practice is effective, motivating and wellvalued by participants in relation to their professional future, observing correlations between these aspects. In particular, positive associations between positive emotions and learning outcomes are detected, and between these and value towards practice; as well as negative association between negative emotions and learning outcomes.

Keywords: Microbiology, Primary Education, practical teaching, teacher training, emotions

Para citar este artículo: Marcos-Merino, J.M., Esteban, R., Gómez, J. (2019) Formando a futuros maestros para abordar los microorganismos mediante actividades prácticas. Papel de las emociones y valoraciones de los estudiantes. Revista Eureka sobre Enseñanza y Divulgación de las Ciencias 16(1), 1602. doi: 10.25267/Rev_Eureka_ensen_divulg_cienc.2019.v16.11.1602 


\section{Introducción}

El mundo microbiano no constituye un contenido motivante para el alumnado de Educación Primaria. Como afirman Vicente, García-Ovalle y Medina (2010), "los microbios no son tan llamativos como los tigres, las ballenas o los árboles de la selva, y no suelen aparecer casi nunca como héroes de películas, cuentos o cómics". Ante esta circunstancia, se ha recomendado implementar actividades prácticas (Faccio et al. 2013) con las que abordar la relación de los microorganismos con la vida cotidiana.

\section{Ideas alternativas de Microbiología en Educación Primaria: influencia de los docentes en su transmisión}

Los alumnos de Educación Primaria tienen una visión incompleta y limitada de los microorganismos, normalmente centrada en su papel como patógenos (Ballesteros, Paños y Ruiz-Gallardo 2018); obviando su importancia en ámbitos como la medicina, el medio ambiente o la producción de alimentos (Harms 2002; Karandon y Sahin 2010). El papel beneficioso, otorgado por algunos alumnos, se restringe a la producción de yogur y a su intervención en la digestión (Ballesteros et al. 2018; Simonneaux 2010). Otras concepciones detectadas en estos estudios son:

- Aunque tienen claro su tamaño microscópico, está muy extendida la idea de que no pueden verse a simple vista, ni aunque se junten muchos microorganismos. Esto evidencia un desconocimiento del cultivo microbiano.

- Falta de identificación como seres vivos capaces de realizar las funciones vitales y formados por células. Por ello, los representan con formas abstractas, humanas o como pequeños animales.

- Desconocimiento de su diversidad, asemejándolos de manera genérica a bacterias.

- Falta de reconocimiento sobre su ubicuidad, asociándolos a lugares sucios. Aunque de modo general los sitúan en el cuerpo humano, desconocen su papel beneficioso y relacionan su presencia con la ausencia de higiene; fundamentalmente en las manos, lugar del cuerpo donde los ubican con mayor frecuencia.

- Incapacidad para diferenciar los conceptos y métodos de esterilización y asepsia.

Muchas de estas concepciones se mantienen tras la Educación Primaria, lo que sugiere que la enseñanza tradicional no es capaz de sustituirlas por los conceptos aceptados por la comunidad científica. Respecto a su origen, Karandon y Sahin (2010) señalan que las principales fuentes de información sobre microorganismos son la escuela y los medios de comunicación. Estos últimos transmiten una visión simple y negativa de los microorganismos como patógenos. En relación a la escuela, muchas concepciones alternativas tienen su origen en una enseñanza inadecuada, influida por las concepciones de los docentes y por las presentes en los libros de texto (Carrascosa 2005). Recientemente, Ballesteros et al. (2018) han comprobado que los libros de texto de Educación Primaria se centran en tratar a los microorganismos como patógenos, al abordarlos dentro del bloque de la salud. Además, en la mayoría se omite su ubicuidad y, en ocasiones, se recurre al antropomorfismo para su representación. Respecto a los maestros, Jones y Rua (2006) han evidenciado que limitan su conocimiento microbiano a las enfermedades, lo que podría favorecer que en sus clases se centren en el papel perjudicial de los microorganismos y no ahonden en sus beneficios y sus aplicaciones biotecnológicas, de las que tienen poco conocimiento. Estas mismas concepciones, así como un desconocimiento de la ubicuidad y de los procedimientos de esterilización y asepsia, han sido detectadas en maestros en formación inicial (Marcos-Merino 
y Esteban 2018). Dado que los maestros constituyen uno de los principales focos de transmisión de ideas alternativas, es necesario atajar esta situación desde la formación inicial.

\section{Emociones hacia la Microbiología: influencia en su enseñanza-aprendizaje}

El mundo microbiano genera emociones negativas en la mayoría de los alumnos de Educación Primaria, quienes se sienten mal al oír hablar de microorganismos y los relacionan con términos como "agresividad", "maldad" o "peligro" (Karandon y Sahin 2010). Esta situación es muy relevante, debido al efecto que las emociones pueden tener en el aprendizaje, por lo que se ha recomendado tenerlas en cuenta en la labor docente (Pekrun 2014). Actualmente, se considera que las emociones forman parte de un proceso con el que valorar acontecimientos y estimar si son deseables para el individuo (Damasio 2010). De este modo, una activación de las emociones positivas puede dar lugar a mejores resultados de aprendizaje, ya que provocan una mejora de la memoria (Kensinger y Corkin 2004). Por otro lado, se ha comprobado que las emociones que los maestros en formación sintieron como alumnos de Educación Primaria se transfieren a las que esperan sentir como docentes (Mellado et al. 2014), y que las emociones experimentadas por los maestros se transfieren a sus alumnos (Frenzel, Goetz, Lüdtke, Pekrun y Sutton 2009). Por tanto, es necesario disminuir, en los maestros, las emociones negativas hacia los microorganismos, para que no las transmitan entre sus alumnos; así como promover emociones positivas que favorezcan su enseñanza.

Una manera de promover emociones positivas es la inclusión de sesiones prácticas (Hofstein y Lunetta 2004). Según Harms (2002), el procedimiento básico a incluir en la enseñanza práctica de los microorganismos es su cultivo, proceso sencillo que permite poner de manifiesto su presencia en colonias. Sin embargo, los maestros realizan pocas actividades prácticas de Microbiología, aduciendo falta de conocimiento, dificultad técnica y temor ante problemas de salud o seguridad (Redfern, Burdass y Verran 2013). Ante esta situación, es necesario formar a los futuros maestros en la enseñanza práctica de Microbiología. Simultáneamente, es necesario indagar en la influencia de estas actividades en las emociones y el aprendizaje (Damasio 2010). Actualmente, nuestro grupo de investigación está investigando el papel de las emociones en el aprendizaje de maestros en formación mediante sesiones prácticas. Para ello hemos diseñado y validado un sencillo cuestionario con el que estimar la intensidad de una serie de emociones (Marcos-Merino, Esteban y Gomez 2016). Resultados preliminares muestran que existe una asociación entre el aprendizaje de Biología Celular adquirido mediante una actividad práctica y las emociones positivas sentidas con esta (Marcos-Merino et al. 2016). Para ahondar en esta relación, en este trabajo se analizan las interacciones entre los resultados de aprendizaje y las emociones experimentadas con una práctica basada en el cultivo microbiano.

\section{Objetivos}

La finalidad del presente trabajo es determinar si existe una asociación entre los resultados de aprendizaje de Microbiología alcanzados con una actividad práctica, el valor subjetivo otorgado a dicha práctica y las emociones experimentadas durante la misma, en una muestra de estudiantes del Grado en Educación Primaria de la Universidad de Extremadura. Para alcanzar este objetivo general se plantean varios objetivos específicos:

- Estimar la intensidad de una serie de emociones ante la expectativa de realizar una práctica de Microbiología y tras su implementación

- Determinar los resultados de aprendizaje alcanzados con la intervención

- Determinar el valor subjetivo que otorgan los estudiantes a la intervención 
- Analizar las asociaciones entre las emociones experimentadas con la intervención, el valor subjetivo y los resultados de aprendizaje

\section{Metodología}

\section{Muestra}

La muestra consiste en 139 futuros maestros (22 años media; 65.9\% mujeres), estudiantes del Grado en Educación Primaria de la Universidad de Extremadura. Solo un 30.1\% de los alumnos cursó una modalidad de ciencias en Bachillerato.

\section{Instrumento}

El instrumento utilizado es un cuestionario que consta de dos partes y se aplica antes de la intervención (para determinar la expectativa de emociones ante la práctica y los conocimientos previos) y 15 días después (para determinar las emociones experimentadas durante la intervención y el aprendizaje). En este cuestionario posterior se incluye, además, una tercera parte, a fin de conocer cómo valoran los participantes la práctica implementada. Para ello se emplea la siguiente pregunta: "Si aprender a sumar tiene un valor de 100 para tu vida diaria, ¿Qué valor le otorgas, en una escala de 0 a 100, a la práctica realizada para tu futuro como docente de Educación Primaria?".

Con la primera parte del cuestionario, relativa a las emociones, se determina la intensidad con la que los participantes experimentaron una serie de emociones antes y después de la intervención. Para ello se emplea un cuestionario autoinforme cuantitativo de ítems simples validado en trabajos previos mediante análisis factorial (Marcos-Merino et al. 2016). El cuestionario autoinforme es el procedimiento más utilizado para estudiar las emociones de los alumnos, ya que constituye una medida rápida que apenas afecta a las actividades de aula. Incluye 10 emociones: 5 positivas (alegría, confianza, satisfacción, entusiasmo y diversión) y 5 negativas (preocupación, frustración, incertidumbre, nerviosismo y aburrimiento). Los alumnos autoinforman, siguiendo una escala ordinal de Likert (oscila desde 1 "no experimentada" a 5 "intensamente experimentada"), sobre la intensidad con la que creían que iban a experimentar (antes de la intervención) o habían experimentado (tras la intervención) dichas emociones.

Respecto a la segunda parte del cuestionario (anexo 1), con ella se evalúa el grado de conocimiento de conceptos básicos de Microbiología. Se aplica como pretest (para determinar el conocimiento previo) y como postest (para determinar los resultados de aprendizaje). Está formado por 15 preguntas cerradas de tipo test y se ha validado siguiendo lo indicado por Smith, Wood y Knight (2008). En primer lugar, se realizó una revisión sobre concepciones alternativas de Microbiología, especialmente aquellas comunes en maestros en formación (Jones y Rua 2006; Marcos-Merino y Esteban 2018). Tras esto, se seleccionaron objetivos de aprendizaje, relacionados con estos contenidos, propios de la ESO, como el nivel en ciencias más alto alcanzado por la mayoría de la muestra. En base a estos se elaboraron algunas preguntas, mientras que otras se extrajeron del TIMSS.

\section{Diseño de la intervención}

La intervención consiste en una práctica de laboratorio y consta de dos fases. En la primera fase se utiliza el cultivo microbiano para abordar conceptos como microorganismo, su ubicuidad y diversidad, colonia, asepsia y esterilización. Esta fase comienza con la lectura y discusión del artículo de prensa "Si se ha caído al suelo, ¿me lo puedo comer?" (https://elpais.com/elpais/2015/01/07/buenavida/1420628686_169625.html). El docente 
genera un debate en el cual los alumnos exponen sus conocimientos previos de Microbiología. Tras esto, evidencia cómo se preparan los medios de cultivo, presentando los materiales fungibles e instrumentos empleados en los laboratorios (placa de Petri, agar nutritivo, agua destilada, autoclave, mecheros...). Para ello, enumera los elementos que componen el agar nutritivo (extracto de levadura y carne, agar, peptona y cloruro sódico) explicitando el papel de cada uno en la formación del medio, y justifica por qué este se disuelve en agua destilada (y no en agua del grifo, debido a la presencia de cloro). Seguidamente, expone qué es un autoclave, su funcionamiento y cómo se emplea para esterilizar el medio. A continuación, aborda cómo repartir el medio nutritivo estéril (una vez extraído del autoclave) en placas de Petri (también estériles) sin la utilización de una campana de flujo laminar, en un ambiente, el laboratorio, que contiene microorganismos. En este momento se profundiza sobre cómo trabajar en condiciones de asepsia: limpiar con alcohol la poyata del laboratorio, encender mecheros alrededor del área de trabajo, cerrar puertas y ventanas para evitar corrientes de aire, trabajar pocas personas, lavarse las manos antes de comenzar, no hablar durante el proceso... Finalmente, comenta las condiciones de almacenaje de los medios de cultivo hasta su utilización: una vez repartido, se deja enfriar hasta que solidifique y, cuando esto ocurre, se guarda en la nevera en bolsas cerradas con las placas invertidas para evitar la condensación sobre el agar.

Tras la explicación, se reparten a los alumnos, organizados en parejas, tres placas con medio nutritivo con las que realizan los siguientes experimentos:

- Experimento 1 (¿Dónde viven los microorganismos?). Para mostrar la ubicuidad de los microorganismos y discutir su diversidad (fundamentalmente diferenciar entre bacterias y hongos), los alumnos dejan abiertas, durante 20 minutos, placas de Petri en distintos lugares de la facultad (aulas, biblioteca, cafetería, baños, laboratorio, salón de actos, pasillo, secretaría, jardín, reprografía...)

A)

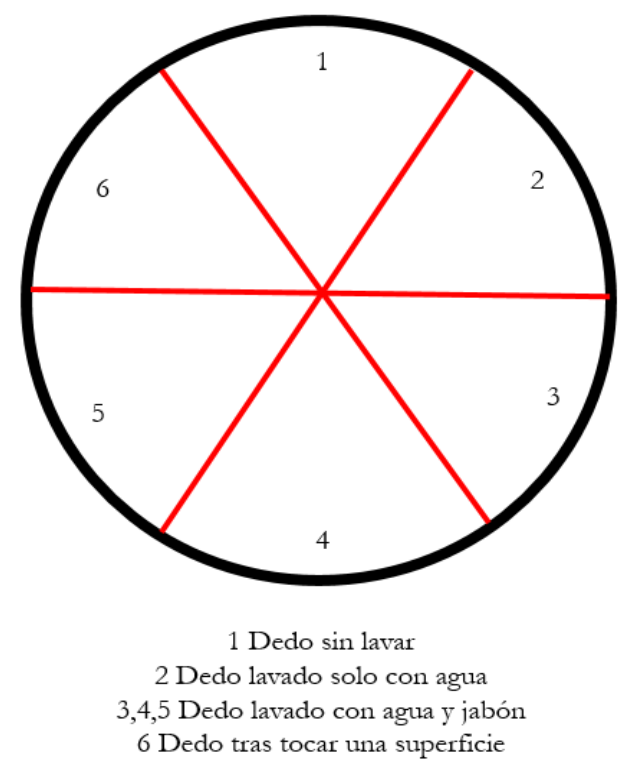

B)

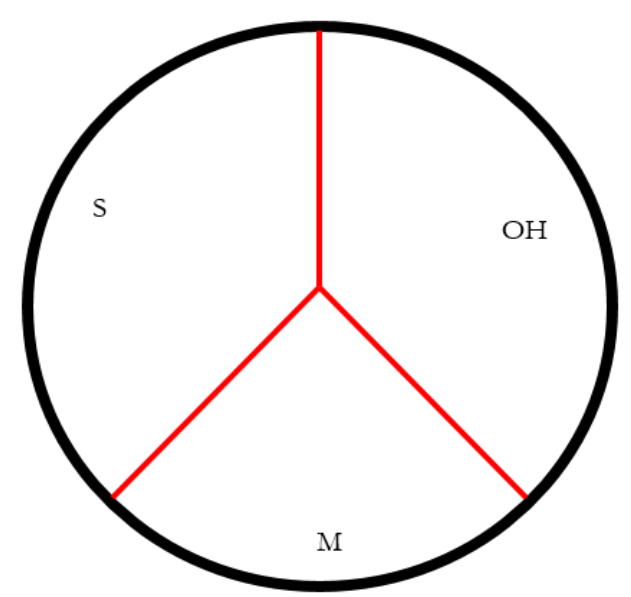

S Dedo lavado solo con agua OH Dedo limpiado con alcohol M Dedo tras tocar una superficie

Figura 1. Pasos a seguir en los experimentos 2 y 3

- Experimento 2 (¿Cuántas veces me lavo las manos?). Para comprobar que lavarse las manos es un método aséptico (elimina solo a algunos microorganismos, hasta el nivel que evita la infección), los alumnos dividen, con un rotulador, una placa de Petri en 6 porciones (Figura 1A), que tocan con el dedo sin lavar (1), lavado solo con agua (2), 
lavado con agua y jabón una, dos y tres veces $(3,4,5)$ y tras tocar una superficie cualesquiera (6). Es importante advertir que el experimento debe realizarlo siempre el mismo alumno, para poder observar el efecto del lavado de manos en la microbiota de las manos; así como indicar la necesidad de escurrir el dedo antes de tocar, para evitar que el agua se transfiera de una porción a otra.

- Experimento 3 (¿Esterilización o asepsia?). Con el fin de comprobar que el alcohol mata a todos los microorganismos, los alumnos dividen, con un rotulador, una placa de Petri en 3 porciones (Figura 1B), que tocan con el dedo lavado solo con agua (S), limpiado con alcohol $(\mathrm{OH})$ y tras tocar una superficie cualesquiera $(\mathrm{M})$

Una semana después vuelven al laboratorio para interpretar y discutir los resultados (Figura 2).

A)
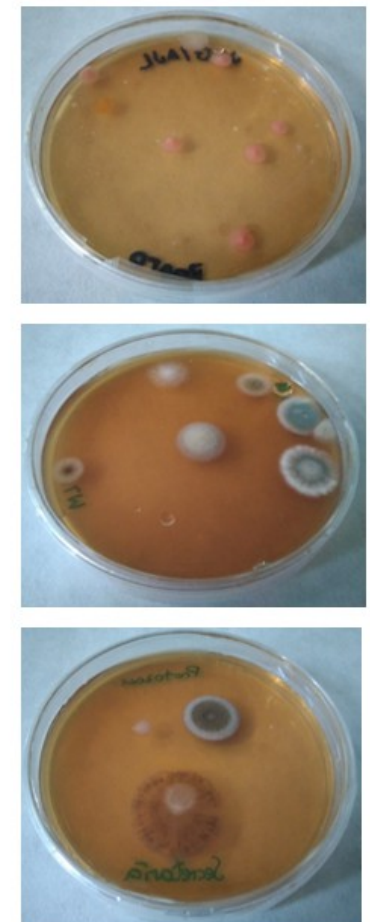

B)
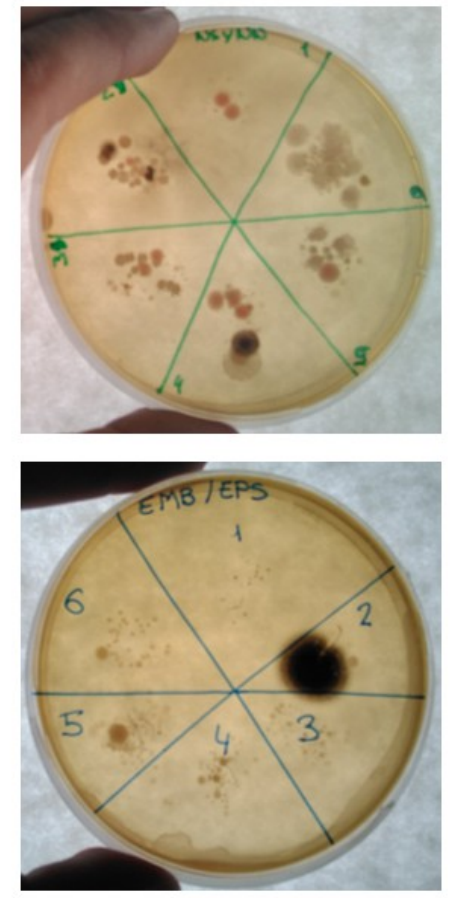

C)
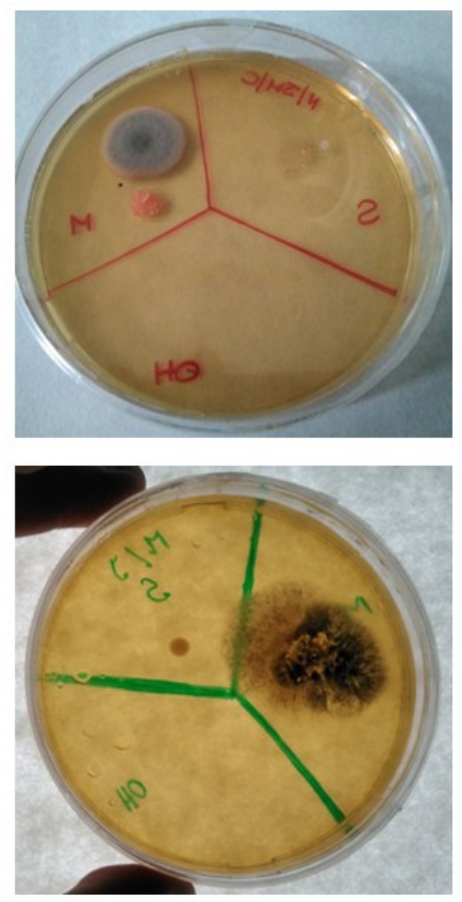

Figura 2. Ejemplos de resultados obtenidos en los experimentos sobre ubicuidad y diversidad (A), asepsia (B) y esterilización (C)

La segunda fase de la intervención tiene como objetivo que los alumnos elaboren un protocolo para realizar la práctica desarrollada en la primera fase con alumnos de Educación Primaria y únicamente con productos cotidianos. Esta fase se implementa a través del modelo didáctico de investigación dirigida (Gormally, Brickman, Hallar y Armstrong 2009). El profesor plantea la siguiente situación: "En la actualidad existen medios nutritivos comerciales para hacer crecer microorganismos. Sin embargo, los maestros no tienen acceso a ellos ni al resto de materiales e instrumentos necesarios para desarrollar una práctica como la implementada en este seminario (placas de Petri, autoclave...). No obstante, históricamente los microbiólogos han sido capaces de cultivar microorganismos con medios nutritivos caseros. Diseña un protocolo para cultivar microorganismos en el cual sólo utilices productos que se puedan obtener en un supermercado. Indica, además, los procedimientos de esterilización del medio y los materiales, así como las condiciones asépticas de trabajo". Tras esto, el profesor formula una serie de preguntas abiertas (Tabla 1), cuyas respuestas proporcionan a los alumnos la información necesaria para elaborar un medio de cultivo con materiales cotidianos. Los alumnos resuelven dichos problemas a través de debates guiados por el docente, en los que emplean sus conocimientos previos, lo aprendido en la primera fase 
de la práctica e información que obtienen al realizar búsquedas bibliográficas con sus dispositivos móviles. El profesor reconduce las respuestas de los alumnos (matizando, reforzando, ampliando y/o cuestionándolas), hasta que la clase en su conjunto consensúa una respuesta para cada pregunta. Utilizando éstas, los alumnos proponen, de nuevo mediante un debate guiado, los pasos necesarios para elaborar un medio de cultivo microbiano con materiales cotidianos.

Tabla 1. Preguntas planteadas para iniciar los debates, intervenciones para guiar a los alumnos y respuestas proporcionadas por estos al final del proceso

\begin{tabular}{|c|c|c|}
\hline $\begin{array}{l}\text { Pregunta inicial planteada } \\
\text { por el docente }\end{array}$ & Intervenciones para guiar el debate & $\begin{array}{l}\text { Respuesta consensuada por los alum- } \\
\text { nos }\end{array}$ \\
\hline $\begin{array}{l}\text { ¿Qué recipiente casero } \\
\text { emplearías en lugar de } \\
\text { una placa de Petri? }\end{array}$ & $\begin{array}{l}\text { Debe compartir las características de } \\
\text { una placa de Petri: recipiente transpa- } \\
\text { rente con base y tapa }\end{array}$ & $\begin{array}{l}\text { Caja de agujas, alfileres, bastoncillos, } \\
\text { bombones, golosinas, abalorios para } \\
\text { pulseras... }\end{array}$ \\
\hline $\begin{array}{l}\text { ¿Qué productos caseros } \\
\text { emplearías para fabricar el } \\
\text { medio de cultivo? } \\
\text { ¿Qué pasos seguirías para } \\
\text { fabricarlo? }\end{array}$ & $\begin{array}{l}\text { Se necesitan productos caseros que } \\
\text { cumplan las siguientes funciones: } \\
\text { a) Fuente de nutrientes } \\
\text { Recordar los componentes del agar nu- } \\
\text { tritivo. Entre ellos está el extracto de } \\
\text { carne. ¿A qué producto casero te re- } \\
\text { cuerda? } \\
\qquad \text { b) Capacidad de crear un gel } \\
\text { Ante la respuesta gelatina, ¿existe otro } \\
\text { producto que cumpla esta función? } \\
\text { ¿Qué ventajas tiene sobre la gelatina? } \\
\text { Al abordar la mezcla de los componen- } \\
\text { tes, ¿es posible utilizar agua del grifo? }\end{array}$ & $\begin{array}{l}\text { Pastillas de caldo de carne (sustitutivo } \\
\text { de extracto de carne y levadura, pepto- } \\
\text { na y cloruro sódico) bajas en sal (ya } \\
\text { que el exceso de sal inhibe el creci- } \\
\text { miento microbiano) } \\
\text { Agar-agar para cocina. Es más reco- } \\
\text { mendable que la gelatina (ambos son } \\
\text { gelificantes pero el agar es un carbohi- } \\
\text { drato que no pueden degradar los mi- } \\
\text { croorganismos, mientras que la gelati- } \\
\text { na sí.) } \\
\text { Agua destilada (agua para plancha), no } \\
\text { del grifo porque contiene cloro } \\
\text { Pasos a seguir: disolver las pastillas de } \\
\text { caldo de carne (2) y láminas de agar-a- } \\
\text { gar (10 gramos, } 5 \text { láminas) en agua des- } \\
\text { tilada (1 litro) }\end{array}$ \\
\hline $\begin{array}{l}\text { ¿Qué procedimiento se- } \\
\text { guirías para esterilizar el } \\
\text { medio de cultivo? }\end{array}$ & $\begin{array}{l}\text { Observa el autoclave, ¿a qué objeto ca- } \\
\text { sero te recuerda? } \\
\text { En un autoclave se aumenta la tempe- } \\
\text { ratura y la presión durante un tiempo, } \\
\text { ¿al funcionamiento de qué utensilio ca- } \\
\text { sero te recuerda? }\end{array}$ & $\begin{array}{l}\text { Introducir la disolución en un bote de } \\
\text { cristal con tapa, cubriéndolo pero sin } \\
\text { cerrarlo del todo } \\
\text { Introducir y cocer dicho bote en una } \\
\text { olla a presión con algo de agua (al esti- } \\
\text { lo del método "baño María"), durante } \\
\text { unos } 20 \text { minutos }\end{array}$ \\
\hline
\end{tabular}


Tabla 1. Continuación

\begin{tabular}{|c|c|c|}
\hline $\begin{array}{c}\text { Pregunta inicial planteada } \\
\text { por el docente }\end{array}$ & Intervenciones para guiar el debate & $\begin{array}{c}\text { Respuesta consensuada por los alum- } \\
\text { nos }\end{array}$ \\
\hline $\begin{array}{l}\text { ¿Qué procedimiento se- } \\
\text { guirías para esterilizar el } \\
\text { medio de cultivo? }\end{array}$ & $\begin{array}{l}\text { Observa el autoclave, ¿a qué objeto ca- } \\
\text { sero te recuerda? } \\
\text { En un autoclave se aumenta la tempe- } \\
\text { ratura y la presión durante un tiempo, } \\
\text { ¿al funcionamiento de qué utensilio ca- } \\
\text { sero te recuerda? }\end{array}$ & $\begin{array}{l}\text { Introducir la disolución en un bote de } \\
\text { cristal con tapa, cubriéndolo pero sin } \\
\text { cerrarlo del todo } \\
\text { Introducir y cocer dicho bote en una } \\
\text { olla a presión con algo de agua (al esti- } \\
\text { lo del método "baño María"), durante } \\
\text { unos } 20 \text { minutos }\end{array}$ \\
\hline $\begin{array}{l}\text { ¿Qué procedimiento se- } \\
\text { guirías para esterilizar el } \\
\text { recipiente? }\end{array}$ & $\begin{array}{l}\text { En nuestro caso, compramos las placas } \\
\text { de Petri estériles. ¿Qué puedes hacer } \\
\text { para esterilizar el recipiente? ¿Qué pro- } \\
\text { cedimientos puedes utilizar para elimi- } \\
\text { nar todos los microorganismos? }\end{array}$ & $\begin{array}{l}\text { Hervir el recipiente } \\
\text { Limpiar el recipiente con alcohol } \\
\text { Flamear el recipiente } \\
\end{array}$ \\
\hline $\begin{array}{l}\text { ¿Qué medidas asépticas } \\
\text { tomarías para repartir el } \\
\text { medio nutritivo esteriliza- } \\
\text { do en los recipientes este- } \\
\text { rilizados? }\end{array}$ & $\begin{array}{l}\text { Imagina que produces el medio en tu } \\
\text { casa, ¿en qué lugar llevarías a cabo este } \\
\text { proceso? ¿Qué pasos seguirías? } \\
\text { Recuerda las medidas asépticas toma- } \\
\text { das en un laboratorio ¿Cuáles pueden } \\
\text { aplicarse en un contexto cotidiano? }\end{array}$ & $\begin{array}{l}\text { El lugar idóneo para realizar este pro- } \\
\text { ceso es una cocina. Pueden tomarse las } \\
\text { siguientes medidas: lavarse las manos } \\
\text { antes de comenzar, trabajar cerca del } \\
\text { fuego de la cocina o de una llama } \\
\text { (como una vela), limpiar bien la enci- } \\
\text { mera con alcohol, trabajar pocas perso- } \\
\text { nas, cerrar puertas y ventanas para evi- } \\
\text { tar corrientes de aire, no hablar duran- } \\
\text { te el proceso... }\end{array}$ \\
\hline $\begin{array}{l}\text { ¿Qué debes hacer una vez } \\
\text { has repartido el medio en } \\
\text { los recipientes? }\end{array}$ & $\begin{array}{l}\text { Recuerda los pasos seguidos en un la- } \\
\text { boratorio }\end{array}$ & $\begin{array}{l}\text { Esperar a que el medio se enfríe y soli- } \\
\text { difique } \\
\text { Guardar los recipientes en una bolsa } \\
\text { cerrada en la nevera hasta su utiliza- } \\
\text { ción }\end{array}$ \\
\hline
\end{tabular}

\section{Análisis estadístico}

Los datos no se ajustan a una distribución normal por lo que se utilizó estadística no paramétrica. Las pruebas empleadas para comparar grupos (test de Wilcoxon), las gráficas y las regresiones lineales se realizaron con el programa Kaleidagraph. Los test de normalidad (Kolmogoro-Smirnov y Shapiro-Wilk), los análisis de correlación (Spearman) y el análisis factorial se realizaron con el programa SPSS. Para la extracción de los factores se emplearon mínimos cuadrados generalizados y una rotación Oblimin. Este método de extracción es robusto frente a la carencia de normalidad y proporciona el test $\chi^{2}$ con el que evaluar el modelo. Se evalúan además la fiabilidad ( $\alpha$ de Cronbach), la medida de adecuación muestral (KMO), la prueba de esfericidad de Bartlett y el porcentaje de varianza explicada. Una vez calculados, los factores fueron guardados como variables centradas. Para realizar correlaciones se emplean valores centrados de las notas y el valor (calculados restando la media y dividiendo por la desviación estándar).

\section{Resultados}

\section{Análisis del cambio de emociones con la intervención}

Los participantes describen sus emociones con diferente intensidad antes y después de la intervención (Figura 3). 


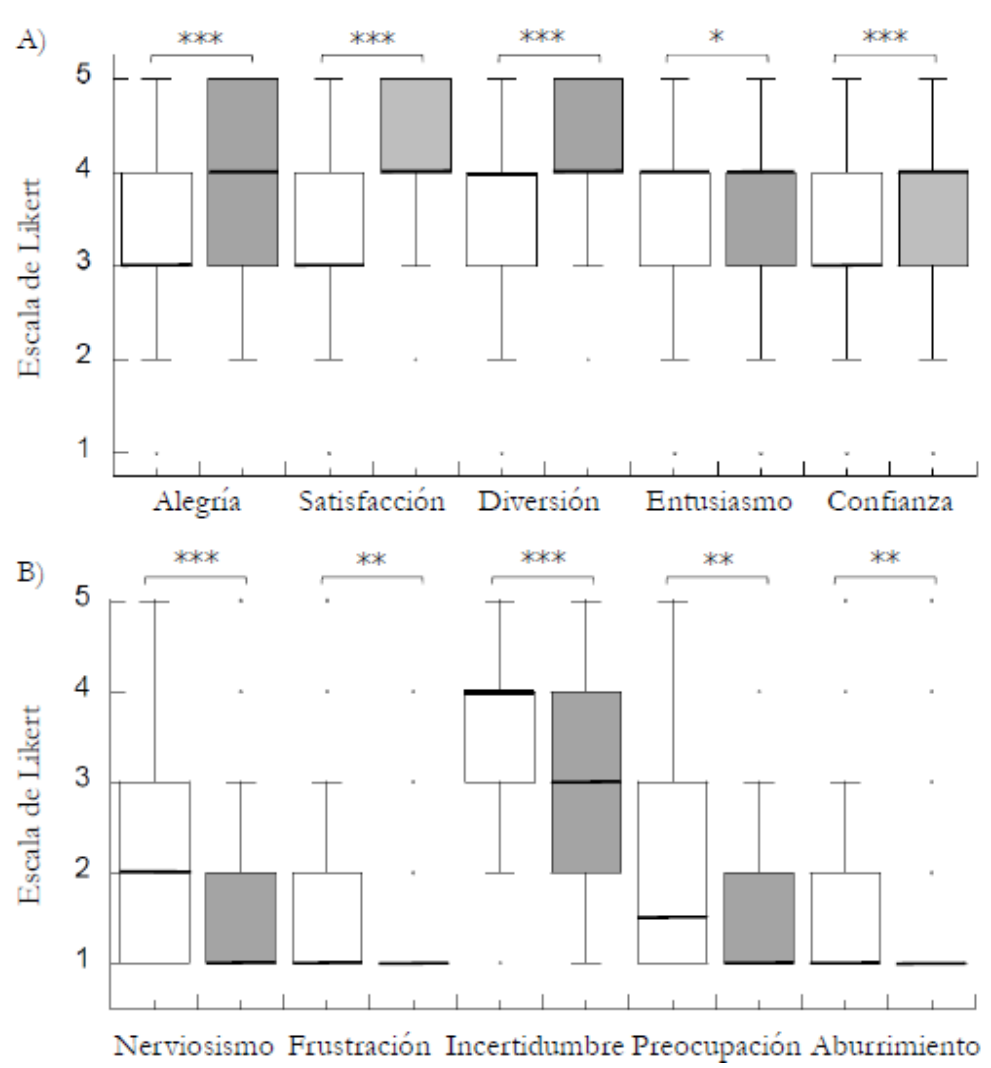

Figura 3. Distribución de la intensidad de las emociones, positivas (A) y negativas (B), antes (cajas vacías) y después (cajas grises) de la intervención. La recta horizontal dentro de cada caja representa la mediana, los límites inferiores y superiores corresponden a los percentiles 25 y 75, y la terminación inferior y superior de las líneas verticales a los percentiles 5 y 95. Las líneas horizontales sobre las cajas unen grupos significativamente diferentes (test de Wilcoxon, ${ }^{* * *}$ p-valor $<.001,{ }^{* *}$ p-valor $<.01,{ }^{*}$ p-valor $<.05$ )

Respecto a su expectativa de emociones antes de realizar la práctica, los alumnos experimentaron con mayor intensidad todas las emociones positivas analizadas y con menor intensidad todas las negativas ( $\mathrm{p}$-valor $<.05$, test de Wilcoxon). En los casos de la alegría, satisfacción y confianza, la mediana aumenta de 3 antes de la intervención a 4 después (pvalor<.001). Respecto a la diversión y al entusiasmo (mediana de 4 antes y después), las diferencias significativas observadas ( $\mathrm{p}$-valor $<.001 \mathrm{y}$ p-valor=.039) se deben a un aumento de la varianza hacia valores superiores. En relación a las emociones negativas, el nerviosismo disminuye desde una mediana de 2 antes de la intervención a 1 después (p-valor<.001), la incertidumbre de una mediana de 4 a 3 (p-valor<.001) y la preocupación de una mediana de 1.5 a 1 (p-valor=.003). Respecto a la frustración y el aburrimiento (mediana de 1 en ambos casos), las diferencias significativas ( $\mathrm{p}$-valor=.003 y p-valor=.008) se deben a una disminución de la varianza hacia valores inferiores.

\section{Análisis factorial: extracción de los factores asociados a las emociones positivas y negativas}

Los datos de intensidad de las emociones antes y después de la intervención fueron sometidos a un análisis factorial (Tabla 2). La KMO era mayor de .7 en ambos casos (.73 antes y .75 después), el test $\chi^{2}$ mayor que .05 (.13 y .07 respectivamente), y la varianza explicada se sitúa en torno al 50\% (51\% antes y 47\% después). Además, la fiabilidad ( $\alpha$ de Cronbach de .7) y la prueba de esfericidad de Bartlett ( $\mathrm{p}$-valor=.000) apoyan la conveniencia de realizar un análisis factorial. Dicho análisis muestra que las emociones se pueden descomponer en dos factores: el factor 1 que correlaciona positivamente con las emociones positivas y el factor 2 que lo hace 
con las negativas. Estos resultados sugirieren que el factor 1 corresponde a las emociones positivas mientras que el factor 2 corresponde a las negativas. La confianza y el aburrimiento además de correlacionarse positivamente con el factor 1 y 2 respectivamente, se correlacionan negativamente con el factor opuesto. Con el objeto de realizar correlaciones entre las emociones positivas y negativas como valores globales y el resto de variables, dichos factores se guardaron como variables centradas.

Tabla 2. Matriz de estructura, en la que se resaltan en negrita las correlaciones superiores a .250

\begin{tabular}{|l|c|c|c|c|}
\hline & \multicolumn{2}{|c|}{$\begin{array}{c}\text { Antes de la } \\
\text { intervención }\end{array}$} & $\begin{array}{c}\text { Después de la } \\
\text { intervención }\end{array}$ \\
\hline & \multicolumn{4}{|c|}{ Matriz de estructura } \\
\hline Emociones & Factor 1 & Factor 2 & Factor 1 & Factor 2 \\
\hline Alegría & $\mathbf{. 7 3 3}$ & .026 & $\mathbf{. 7 6 9}$ & .023 \\
\hline Confianza & $\mathbf{. 4 3 5}$ & -.438 & .467 & -.221 \\
\hline Satisfacción & $\mathbf{. 7 0 8}$ & .043 & $\mathbf{. 7 8 1}$ & -.150 \\
\hline Entusiasmo & $\mathbf{. 6 3 8}$ & .170 &. $\mathbf{7 3 3}$ & .063 \\
\hline Diversión & $\mathbf{. 7 9 6}$ & .059 & $\mathbf{. 7 0 9}$ & .052 \\
\hline Nerviosismo & .143 & $\mathbf{. 7 0 4}$ & .129 & $\mathbf{. 6 0 4}$ \\
\hline Aburrimiento & $\mathbf{- . 3 0 7}$ & $\mathbf{. 1 5 1}$ & -.299 &. $\mathbf{2 5 2}$ \\
\hline Frustración & -.057 & $\mathbf{. 6 2 2}$ & -.140 & $\mathbf{. 5 2 7}$ \\
\hline Preocupación & -.073 & $\mathbf{. 7 8 1}$ & -.223 & $\mathbf{. 5 2 3}$ \\
\hline Incertidumbre & .048 & $\mathbf{. 2 8 2}$ & .027 & $\mathbf{. 2 6 1}$ \\
\hline
\end{tabular}

\section{Análisis de los resultados de aprendizaje}

Al comparar las notas obtenidas por los participantes en las preguntas de contenidos antes y después de la intervención, se observa que la práctica es efectiva en relación al aprendizaje de Microbiología (aumento significativo desde una mediana de 4.67 en el pretest a una mediana de 6 en el postest, p-valor <.001, test de Wilcoxon) (Figura 4). Además, al analizar individualmente las preguntas del test se observa un incremento significativo ( $\mathrm{p}$-valor $<.05$, test de Wilcoxon) en el porcentaje de acierto de preguntas relativas a conceptos microbiológicos básicos como los microorganismos como seres vivos que realizan las funciones vitales (de un $50 \%$ a un $71,94 \%$, p-valor $=.027$ ), las bacterias y los hongos como microorganismos que son seres vivos (de un $18.04 \%$ a un $48,20 \%$, p-valor=.013), la esterilización (de un $23.84 \%$ a un $63,31 \%$, p-valor $<.001$ ), la asepsia (de un $46.60 \%$ a un $68,35 \%$, p-valor $<.001$ ), la patogenicidad como característica solo de algunos microorganismos (de un $37.79 \%$ a un $52 \%$, p-valor $<.001$ ) y el agua como requerimiento nutricional básico de todos los microrganismos (de un $12.79 \%$ a un $29,50 \%$, p- valor $=.004)$. 


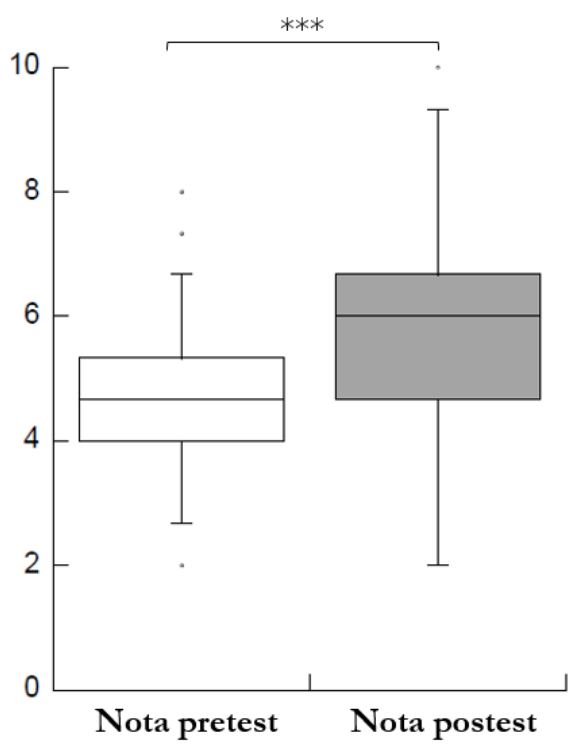

Figura 4. Distribución de los resultados obtenidos por los alumnos en el pretest (caja vacía) y en el postest (caja gris). La recta horizontal dentro de cada caja representa la mediana, los límites inferiores y superiores corresponden a los percentiles 25 y 75, y la terminación inferior y superior de las líneas verticales a los percentiles 5 y 95. Las líneas horizontales sobre las cajas unen grupos significativamente diferentes (test de Wilcoxon, *** pvalor $<.001)$

\section{Valor subjetivo otorgado a la práctica}

Respecto al valor otorgado por los estudiantes a la práctica implementada, se obtiene una mediana de 80 (rango intercuartílico de 20). Esto sugiere que el alumno considera útiles los conocimientos adquiridos.

\section{Análisis de las relaciones entre aprendizaje, emociones y valor subjetivo}

Los análisis de correlación reflejan una asociación significativa entre la intensidad de algunas emociones sentidas en la práctica y los resultados de aprendizaje, medidos con la nota del postest (Tabla 3). Se observan correlaciones positivas entre la nota del postest y la confianza ( $\mathrm{p}$-valor $<.001)$, el entusiasmo ( $\mathrm{p}$-valor=.006), la diversión ( $\mathrm{p}$-valor=.02) y la satisfacción ( $\mathrm{p}$ valor=.023); así como una correlación negativa con el nerviosismo ( $\mathrm{p}$-valor=.028). Estos resultados indican que los alumnos que obtuvieron mejores resultados en el postest son aquellos que sintieron con mayor intensidad confianza, satisfacción, entusiasmo y diversión, así como menos nerviosismo. El análisis de los factores latentes confirma estas observaciones (Figura 5A), ya que muestra que los participantes que obtuvieron mejores resultados son aquellos que sintieron con mayor frecuencia emociones positivas ( $\mathrm{p}$-valor $=.006$ ) y con menor frecuencia emociones negativas ( $\mathrm{p}$-valor=.033). 
Tabla 3. Coeficientes de correlación de las emociones, individuales (izquierda) y factores (derecha), con la nota del postest. En negrita se resaltan las correlaciones significativas (Spearman, $* * * \mathrm{p}-\mathrm{valor}<.001$, $* *$ p-valor $<.01, *$ p-valor $<.05$ )

\begin{tabular}{|c|c|c|c|}
\hline $\begin{array}{l}\text { Emociones } \\
\text { individuales }\end{array}$ & $\begin{array}{l}\text { Correlación con la nota del } \\
\text { postest }\end{array}$ & Factores & $\begin{array}{c}\text { Correlación con la nota del } \\
\text { postest }\end{array}$ \\
\hline Alegría & .131 & \multirow{5}{*}{$\begin{array}{c}\text { Emociones } \\
\text { positivas }\end{array}$} & \multirow{5}{*}{$.234 * *$} \\
\hline Confianza & $.324 * * *$ & & \\
\hline Satisfacción & $.197 *$ & & \\
\hline Entusiasmo & $.238 * *$ & & \\
\hline Diversión & $.201 *$ & & \\
\hline Nerviosismo & $-.189 *$ & \multirow{5}{*}{$\begin{array}{c}\text { Emociones } \\
\text { negativas }\end{array}$} & \multirow{5}{*}{$-.185^{*}$} \\
\hline Aburrimiento & -.090 & & \\
\hline Frustración & -.113 & & \\
\hline Preocupación & -.103 & & \\
\hline Incertidumbre & -.060 & & \\
\hline
\end{tabular}

Respecto al valor otorgado a la práctica, se ha detectado una correlación de .211 (pvalor=0014) entre este y la nota del postest (Figura 5B). Esta observación indica que aquellos alumnos que valoran mejor la práctica implementada, como herramienta para su futuro como maestros, son aquellos que han obtenido mejores resultados de aprendizaje. Respecto al análisis de las correlaciones entre las emociones y el valor, solo se ha detectado una correlación de .217 ( $\mathrm{p}$-valor=.02) entre este y la intensidad de entusiasmo sentido durante la práctica. No se observan correlaciones significativas con los factores de las emociones.
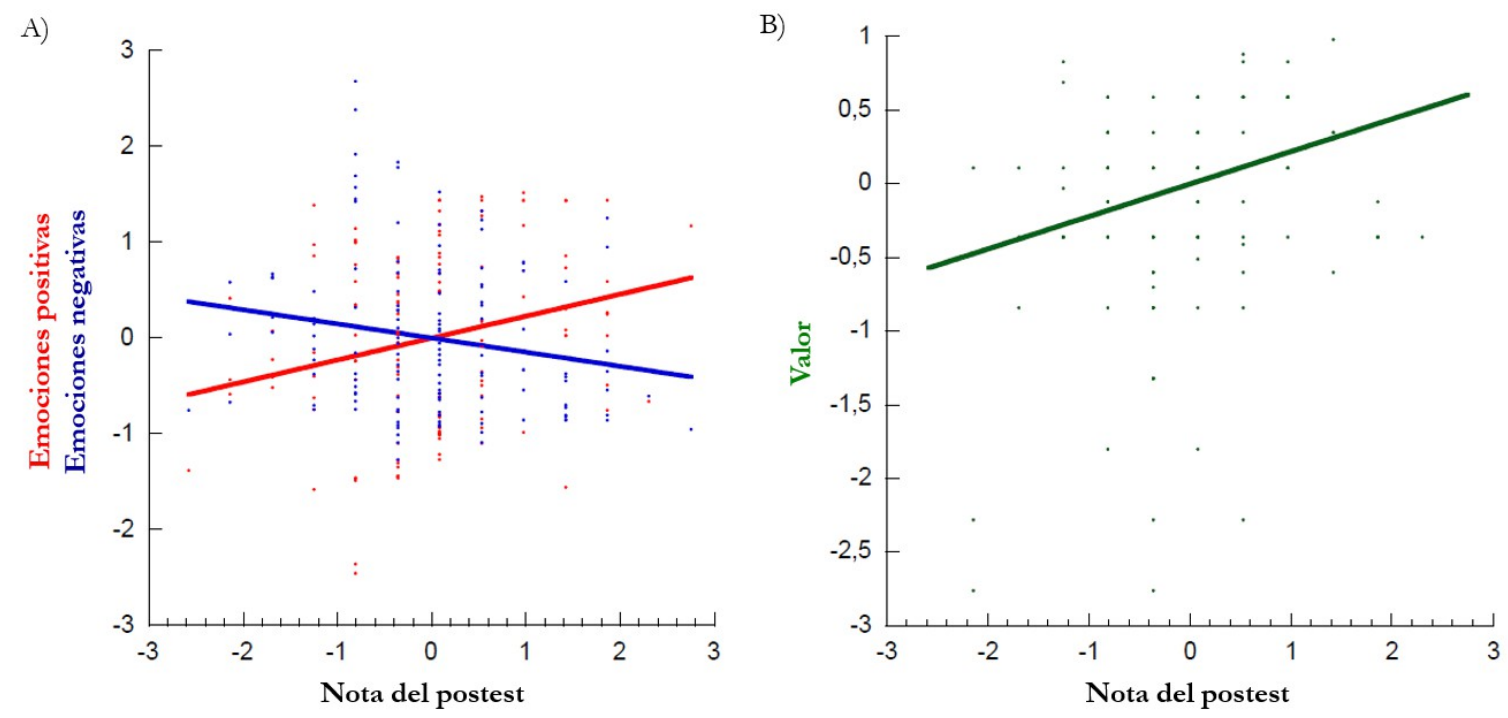

Figura 5. Regresión lineal entre la nota del postest y los factores de las emociones positivas (rojo A), negativas (azul A) y valor (B)

\section{Discusión e implicaciones formativas}

Los resultados de esta investigación muestran que la práctica diseñada es efectiva, motivante y bien valorada por los participantes en relación a su futuro profesional; observándose correlaciones entre estas variables. En lo relativo al domino afectivo, la intervención generó una mayor intensidad de emociones positivas y una menor intensidad de emociones negativas respecto a la expectativa inicial. Esto concuerda con estudios previos que han demostrado el papel motivador de las prácticas (Hofstein y Lunetta 2004), especialmente de aquellas desarrolladas bajo investigación dirigida (Marcos-Merino et al. 2016). Los resultados se 
asemejan a lo observado por Retana-Alvarado, De las Heras-Pérez, Vázquez-Bernal y Jiménez-Pérez (2018), quienes han mostrado que la enseñanza de las ciencias bajo este modelo, a maestros en formación, provoca una mayor frecuencia de emociones positivas, así como una disminución en la frecuencia de las negativas. Teniendo en cuenta que las emociones que sienten los maestros se transfieren a sus alumnos (Frenzel et al. 2009), podría resultar relevante incluir, en los procesos de formación inicial, este tipo de prácticas activas como estrategias para la enseñanza de Microbiología. De este modo, al generar en los futuros maestros emociones positivas hacia los microorganismos, estos las podrán promover entre sus alumnos (Damasio 2010), así como contribuir a reducir las emociones negativas tan extendidas hacia estos contenidos (Ballesteros et al. 2018). Por otro lado, las emociones presentan un comportamiento factorial similar al mostrado en investigaciones previas (Marcos-Merino et al. 2016; Pekrun, Goetz, Frenzel, Barchfeld y Perry 2011). Destaca el comportamiento singular del aburrimiento y la confianza que, además de asociarse positivamente con su factor, se asocian negativamente con el factor opuesto. Esta observación ya ha sido apuntada por marcos-Merino et al. (2016) para el aburrimiento, y sugiere que una intervención sobre estas emociones permite atenuar las emociones negativas e incrementar las positivas a la vez. Por ello, para mejorar las emociones de los alumnos hacia la Microbiología, se aconseja intervenir en primer lugar sobre ambas emociones.

En relación al dominio cognitivo, los resultados muestran que la intervención es efectiva, lo que puede deberse, como han mostrado trabajos previos, a sus características potenciales. Así, se ha descrito que las actividades prácticas de Microbiología son más eficaces que las expositivas (Faccio et al. 2013; Redfern et al. 2013). Respecto al modelo didáctico empleado, se ha mostrado que las actividades desarrolladas bajo investigación dirigida proporcionan mejores situaciones de aprendizaje (Marcos-Merino et al. 2016; Gormally et al. 2009). Además, el proceso de aprendizaje social, llevado a cabo mediante los debates planteados, mejora la comprensión y la memoria (Edelson, Sharot, Dolan y Dudai 2011). Y en cuanto a la utilidad del contenido impartido, Hulleman y Harackiewicz (2009) indican que realizar actividades en las que se resalta la aplicabilidad de los contenidos mejora el rendimiento. Este hecho está respaldado por la asociación detectada entre los resultados de aprendizaje y el valor otorgado a la práctica. Estos resultados surgieren incorporar, en la formación inicial, actividades prácticas desarrolladas bajo investigación dirigida, con las que se fomente el aprendizaje entre iguales y que los alumnos perciban como útiles para su futuro como maestros.

Respecto a la relación entre aprendizaje y emociones, se ha detectado una asociación positiva entre el factor de las emociones positivas y los resultados de aprendizaje, y una asociación negativa entre estos y el factor de las negativas. Esta observación coincide con estudios previos (Pekrun et al. 2011) que han apuntado que las emociones experimentadas durante los procesos de enseñanza afectan a los resultados de aprendizaje (las positivas se asocian positivamente a este mientras que las negativas se asocian negativamente). De igual modo, concuerdan con trabajos que han demostrado que la información relacionada con algún estímulo emocional se recuerda mejor que la neutra (Dunsmoor, Murty, Davachi y Phelps 2015). Al analizar las correlaciones entre las emociones individuales y la nota del postest, se observa que la mayoría de las correlaciones se producen con emociones positivas. Este hecho se ajusta a investigaciones previas que han detectado que una activación de las emociones positivas puede dar lugar a mejores resultados de aprendizaje (Kensinger y Corkin 2004). Estos resultados sugieren que el aprendizaje de Microbiología podría ser favorecido si se plantearan actividades prácticas con las que se disminuyesen las emociones negativas, fundamentalmente nerviosismo, y se aumentasen las emociones positivas; sobre todo confianza, satisfacción, entusiasmo y diversión. La asociación detectada entre emociones y aprendizaje no permite establecer una determinada causalidad, pero sugiere que las emociones 
mejoran el aprendizaje y/o el aprendizaje estimula a las emociones. Se requieren, por tanto, futuros estudios con los que profundizar en el papel de las emociones en el aprendizaje. Aun así, los resultados revelan que existe una asociación entre ambas variables, ya que las personas están motivadas para recordar detalles de eventos emocionales, debido a que esta información es útil para su futuro (Dunsmoor et al. 2015). A pesar de esto, no se han detectado correlaciones significativas entre el valor subjetivo otorgado por los estudiantes a la práctica y las emociones, salvo una asociación positiva con el entusiasmo sentido en la intervención.

\section{Conclusiones}

La enseñanza práctica de Microbiología a maestros en formación; acompañada de una discusión, bajo investigación dirigida, sobre cómo elaborar un medio de cultivo microbiano con material cotidiano; es efectiva, genera cambios significativos en sus emociones (incremento de las emociones positivas y descenso de las negativas) y es bien valorada por estos de cara a su futuro profesional. Las asociaciones observadas entre los resultados de aprendizaje, las emociones y el valor otorgado por los participantes sugieren la necesidad de implementar este tipo de actividades prácticas en la formación inicial de maestros, a fin de mejorar su competencia y sus emociones hacia la enseñanza de los microorganismos.

\section{Agradecimientos}

Este estudio ha sido financiado por el Proyecto de Investigación EDU2016-77007-R del Ministerio de Economía y Competitividad y por la Ayuda a Grupos GR18004 de la Junta de Extremadura y el Fondo de Desarrollo Regional. José María Marcos es beneficiario de una beca FPU del Ministerio de Educación, Cultura y Deportes.

\section{Referencias}

Ballesteros M. I., Paños E., Ruiz J. R. (2018) Los microorganismos en la educación primaria: ideas de los alumnos de 8 a 11 años e influencia de los libros de texto. Enseñanza de las ciencias 36(1), 79-98

Carrascosa J. (2005) El problema de las concepciones alternativas en la actualidad (parte I). Análisis sobre las causas que la originan y/o mantienen. Revista Eureka sobre Enseñanza y Divulgación de las Ciencias 2(2), 183-20

Damasio A. (2010) Y el cerebro creó al hombre. Barcelona: Destino

Dunsmoor J., Murty V., Davachi L., Phelps E. (2015) Emotional learning selectively and retroactively strengthens memories for related events. Nature 520, 345-348

Edelson M., Sharot T., Dolan R., Dudai Y. (2011) Following the crowd: brain substrates of long-term memory conformity. Science 333(6038), 108-111

Faccio E., Costa N., Losasso C., Cappa V., Mantovani C., Cibin V., Andrighetto I., Ricci A. (2013) What programs work to promote health for children? Exploring beliefs on microorganisms and on food safety control behavior in primary schools. Food Control 33(2), 320-329

Frenzel A., Goetz T., Lüdtke O., Pekrun R., Sutton R. (2009) Emotional transmission in the classroom: exploring the relationship between teacher and student enjoyment. Journal of educational psychology 101(3), 705-716

Gormally C., Brickman, P., Hallar B., Armstrong N. (2009) Effects of inquiry-based learning on students' science literacy skills and confidence. International journal for the scholarship of teaching and learning 3(2), 16-22 
Harms U. (2002) Biotechnology education in schools. Electronic Journal of Biotechnology 5(3), 5-6

Hofstein A., Lunetta V. (2004) The laboratory in science education: Foundations for the twenty-first century. Science education 88(1), 28-54

Hulleman C., Harackiewicz J. (2009) Promoting interest and performance in high school science classes. Science 326 (5958), 1410-1412

Jones M., Rua M. (2006) Conceptions of germs: Expert to novice understandings of microorganisms. Electronic Journal of Science Education 10(3), 1-40

Karadon H. D., Şahin N. (2010) Primary school students' basic knowledge, opinions and risk perceptions about microorganisms. Procedia-Social and Behavioral Sciences 2(2), 4398-4401

Kensinger E., Corkin S. (2004) Two routes to emotional memory: Distinct neural processes for valence and arousal. Proceedings of the National Academy of Sciences of the United States of America 101(9), 3310-3315

Marcos-Merino J. M., Esteban R. (2018). Concepciones alternativas sobre Biología Celular y Microbiología de los maestros en formación: implicaciones de su presencia. Campo Abierto 6(2), 167-179

Marcos-Merino J. M., Esteban R., Gómez J. (2016). Efecto de una práctica docente diseñada partiendo de las emociones de maestros en formación bajo el enfoque Ciencia, Tecnología y Sociedad. Indagatio didactica 8(1), 143-157

Mellado V., Borrachero A., Dávila M., Melo L., Brígido M. (2014) Las emociones en la enseñanza de las ciencias. Enseñanza de las ciencias 32, 11-36

Pekrun, R. (2014) Emotions and learning. Ginebra: International Academy of Education/International Bureau of Education.

Pekrun R., Goetz T., Frenzel A., Barchfeld P., Perry R. (2011) Measuring emotions in students' learning and performance: The Achievement Emotions Questionnaire (AEQ). Contemporary educational psychology 36(1), 36-48

Redfern J., Burdass D., Verran J. (2013) Practical microbiology in schools: a survey of UK teachers. Trends in microbiology 21(11), 557-559

Retana D. A., De las Heras-Pérez M. Á., Vázquez-Bernal B., Jiménez-Pérez R. (2018) El cambio en las emociones de maestros en formación inicial hacia el clima de aula en una intervención basada en investigación escolar. Revista Eureka sobre Enseñanza y Divulgación de las Ciencias 15(2), 1-16

Simonneaux L. (2000) A study of pupils' conceptions and reasoning in connection with 'microbes', as a contribution to research in biotechnology education. International Journal of Science Education 22(6), 619-644

Smith M., Wood W., Knight J. (2008). The genetics concept assessment: a new concept inventory for gauging student understanding of genetics. CBE- Life sciences Education 7(4), 422-430

Vicente M., Garcia-Ovalle M., Medina J. (2010) Ni contigo ni sin ti (Guía para entender los microbios). Madrid: Ediciones Grand Guignol 


\section{Anexo 1}

Responde a las siguientes preguntas (sólo una opción es correcta)

1. ¿Cómo de esterilizada está la punta de una aguja que ha sido flameada con un mechero?

a) Totalmente esterilizada

b) Muy esterilizada

c) Casi esterilizada

d) Poco esterilizada

2. Respecto a las funciones vitales realizadas por los microorganismos:

a) Realizan la nutrición, la relación y la reproducción

b) Realizan la nutrición y la reproducción

c) No realizan la nutrición ya que es propia de vertebrados

d) No realizan ninguna función vital

3. Señala la afirmación correcta

a) Un microorganismo lo es sólo mientras no se ve a simple vista

b) Un microorganismo es un ser vivo que no se ve a simple vista

c) Un moho creciendo sobre una fruta no es un microorganismo

d) Los microorganismos no se ven ni aunque se junten millones

4. Después de tocar los fluidos de un enfermo de gripe debes lavarte las manos:

a) Para esterilizarlas

b) Como medida de asepsia

c) Para quitar la suciedad

d) Para activar al sistema inmune

5. ¿Qué puede proporcionar al cuerpo humano inmunidad contra algunas enfermedades por un largo periodo de tiempo?
a) Antibióticos
b) Vitaminas
c) Vacunas
d) Glóbulos rojos

6. ¿Dónde vivían los microorganismos cuando aparecieron en la Tierra?
a) En el agua
b) En el aire
c) Sobre el suelo
d) Bajo el suelo 
7. ¿Cuál de los siguientes elementos es indispensable para que pueda crecer un microorganismo?
a) Azúcar
b) Oxígeno
c) Agua
d) Luz solar

8. ¿Con qué objetivo se añade cloro al agua?
a) Para sanearla
b) Para esterilizarla
c) Para hacerla aséptica
d) Para aromatizarla

9. ¿Cuál de los siguientes microorganismos realizan las funciones vitales?
a) Bacterias y levaduras
b) Bacterias y virus
c) Sólo bacterias
d) Sólo virus

10. Señala la afirmación correcta:

a) Todos los microorganismos son patógenos

b) Ningún microorganismo es patógeno

c) Sólo algunos microorganismos son patógenos

d) La mayoría de los microorganismos son patógenos

11. Algunos microorganismos se utilizan para fabricar alimentos como pan o yogur. ¿Por qué podemos comer estos alimentos?
a) Porque los microorganismos están muertos
b) Porque los microorganismos del pan horneado están muertos y en el caso del yogur están medio muertos
c) No importa que tengan microorganismos, ya que éstos son comestibles
d) Porque los microorganismos están vivos y activan nuestras defensas para matarlos

12. ¿En cuál de los siguientes ambientes no hay microorganismos?
a) En el aire del campo
b) En la sangre de un individuo sano
c) Sobre una mesa limpia
d) En las profundidades marinas 
13. ¿A qué microorganismos matan los antibióticos?
a) Virus
b) Bacterias
c) Todos los microorganismos
d) Hongos

14. En una extracción de sangre te tratan la zona con alcohol antes de pincharte para:
a) Enfriar la zona y que se vea mejor la vena
b) Desinfectar la zona
c) Limpiar la zona
d) Ninguna de las anteriores es correcta

15. Imagina que trabajas en un restaurante. ¿Después de qué acción hay lavarse las manos?
a) Después de ir al baño
b) Después de cobrar
c) Después de manipular otros alimentos
d) Todas las anteriores son ciertas 